devenir Vol. 5, N¹0, JULIO - DICIEMBRE 2018, PP. 29-46 - ESTUDIOS I ISSN 2312-7562 | E-ISSN 2616-4949

UNIVERSIDAD NACIONAL DE INGENIERÍ, LIMA

DOI: https://doi.org/10.21754/devenir.v5i10.597

\title{
TORREONES DE VALDIVIA: VESTIGIOS DE LA CIUDAD AMURALLADA ${ }^{(*)}$
}

\author{
VALDIVIA'S TURRETS: \\ VESTIGES OF THE WALLED CITY \\ LORENA LIEWALD-DESSY ${ }^{[\star]}$ \\ Centro de Estudios Cervantinos, Universidad San Sebastián (Chile) \\ lorena.liewald@uss.cl \\ Fecha de recepción: 30 de marzo de 2018 \\ Fecha de aprobación: 01 de junio de 2018
}

\section{RESUMEN}

La ciudad de Valdivia se transformó, tras su refundación en 1647, en una ciudad amurallada. Durante los siglos XVII y XVIII, se estructuró un proceso que tuvo el objetivo, en forma permanente, de perfeccionar la muralla o cerco, tanto debido a condiciones climáticas y geográficas como por los requerimientos propios de la ingeniería militar. Como parte de ese proceso se levantaron dos torreones en el último cuarto del siglo XVIII, pues se consideraba necesario fortalecer dos puntos considerados estratégicos y vulnerables de la ciudad. Con ello, se pretendía no solo proteger a la población, sino también consolidar el avance hacia zonas que aún se encontraban bajo dominio mapuche-huilliche. Durante la segunda década del siglo XX, ambos torreones fueron declarados Monumento Histórico. Se trata de dos postales que identifican a la ciudad, actualmente sin vínculo con el contenido y el sentido para el cual fueron edificadas.

\section{PALABRAS CLAVE}

Torreones, muralla, Valdivia, memoria

\section{ABSTRACT}

Valdivia City suffered a transformation after its refoundation in 1647 as a walled city. During the XVII and the XVIII century a process of consecutive improvement for the walls or fences was pursuit. All this was a product of the climatic and geographic situations, as well as military engineering requirements. In this process two Turrets were built by the same quarter of the XVIII. Its origin was justified by the need of strengthening two points considered as strategic and vulnerable in the city. Moreover, population protection was not the only purpose, but also to consolidate the progress to other zones, which by that time were under mapuche-huilliche domain. During the second decade of the $X X$, both turrets were declared as Historical Monument. These are two postcards which identify the city, but they lack the meaning and sense by which they were built.

\section{KEYWORDS}

Turrets, wall, Valdivia, memory

${ }^{*}$ )Este artículo es parte de la tesis de maestría desarrollada por la autora para el programa de Patrimonio Artístico y Cultural de Sudamérica de la Universidad de Buenos Aires (UBA), titulada San Luis de Alba de Cruces: Eje Articulador del Territorio. Desde el Marqués de Mancera al Modelo de Vauban.

$\left.{ }^{* *}\right)$ Lorena Liewald-Dessy es profesora de Historia, Geografía y Educación Cívica, magíster en Ciencias Sociales, y en Patrimonio Artístico y Cultural de Sudamérica Colonial por la UBA. Forma parte, en calidad de experta regional, de la Comisión Asesora de Monumentos Nacionales en la Región de los Ríos. Durante su carrera profesional ha realizado una serie de proyectos vinculados con el rescate de la Historia local y el patrimonio. Actualmente es directora del Centro de Estudios Cervantinos de la Universidad San Sebastián, sede Valdivia. 
devenir Vol. 5, Nº10, JULIO - DICIEMBRE 2018, PP. 29-46 - EstudIOS | ISSN 2312-7562 | E-ISSN 2616-4949

UNIVERSIDAD NACIONAL DE INGENIERÍA, LIMA

DOI: https://doi.org/10.21754/devenir.v5i10.597

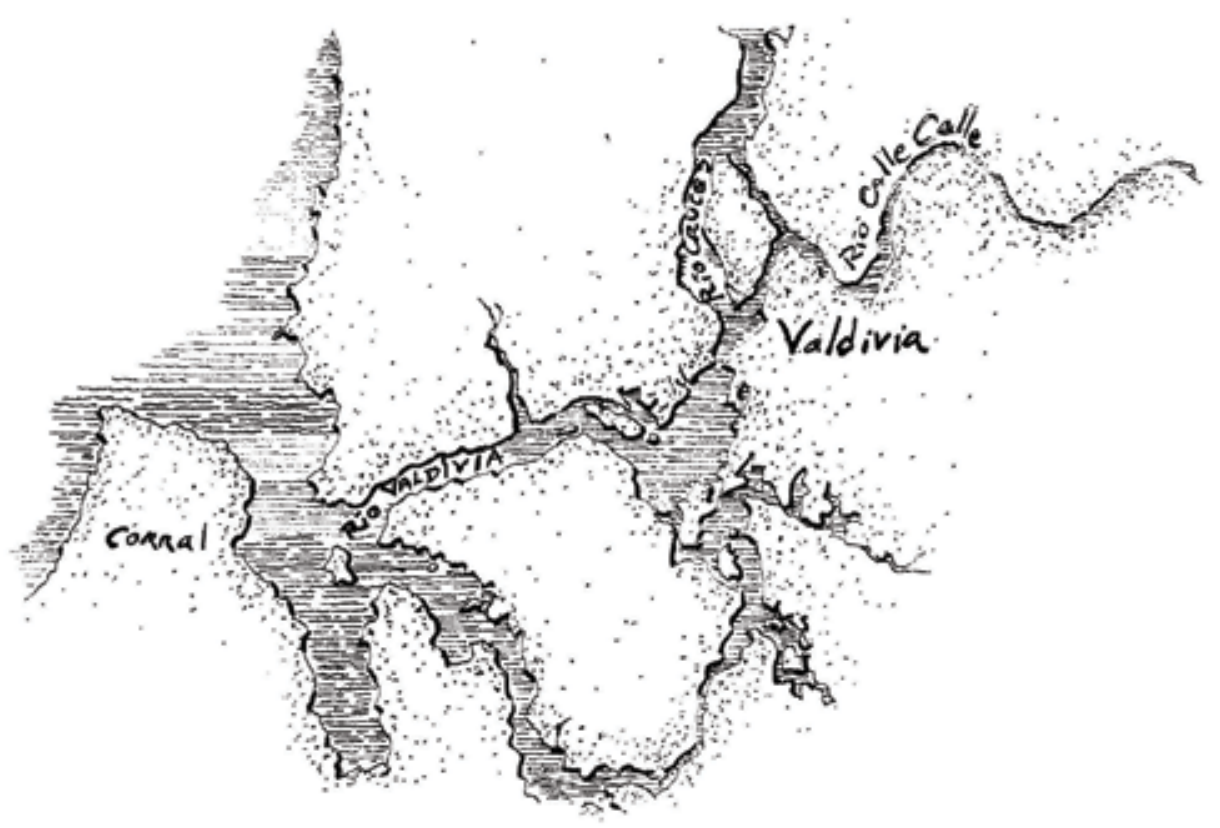

Figura 1. Esquema de la Bahía de Corral, también llamada de Valdivia, y río homónimo. En Club de Yates Valdivia 1912-2012. Cien Años de Travesías en el Mar del Sur (p. 15), por L. Liewald, 2012, Santiago de Chile, Chile: Universidad San Sebastián.

La ciudad de Valdivia, en Chile, fue fundada el 9 de febrero de 1552 por el conquistador don Pedro de Valdivia. Esta se encuentra en los 39048' de latitud sur y $73^{\circ} 15^{\prime}$ de longitud oeste, en un emplazamiento de carácter fluvial: “Dos grandes ríos concurren a formar el río Valdivia en la ciudad del mismo nombre, a 15 km del Océano Pacífico: el Calle Calle, que proviene del oriente, y el Cruces, que se origina con el nombre de San José Copihuelpi" (Liewald, 2012, p. 15). La ciudad se fundó con el objetivo de incorporar de manera efectiva el territorio, además de conectar la capital, Santiago, con el estrecho de Magallanes. En ese esquema, la recién fundada ciudad se transformó en un eslabón de la cadena en pos de la unidad del territorio, al cual siguieron otros intentos fallidos, tales como Nombre de Dios y Rey don Felipe' (Figura 1).

La población aborigen ubicada al sur del río Bio Bio presentó una tenaz resistencia al dominio español, lo cual significó un estado de alarma permanente para el Estado, pues cada cierto tiempo tenía lugar algún tipo de levantamiento. Los malos tratos dados a los indígenas, la falta de recursos de la Real Hacienda, las continuas victorias que los indígenas obtenían sobre los españoles y la ineficiencia de sus fuerzas militares determinaron la gran derrota que las tropas del gobernador don Garcia Oñez de Loyola (1592-1598) sufrieron en la batalla de Curalaba. Con ello se dio inicio al llamado "desastre de Curalaba", entre cuyas consecuencias cuenta el despoblamiento de las siete ciudades situadas entre el río Bio Bio y el canal de Chacao, llamadas "ciudades del sur".2.

\footnotetext{
1. Ambas ciudades fueron fundadas por Pedro Sarmiento de Gamboa en febrero de 1584. La primera aparece en algunos nombrada como Nombre de Jesús, cuyos habitantes se trasladaron a Rey don Felipe. En cuanto a esta última, ha pasado a la historia con el nombre Puerto del Hambre, pues se salvaron de la muerte solo dos habitantes.

2. Además de Valdivia, las ciudades destruidas producto del gran alzamiento fueron Santa Cruz de Coya, San Andrés de los Infantes, San Felipe de Arauco, La Imperial, Villarrica y Osorno.
} 
Entre estas, la ciudad de Valdivia tampoco pudo resistir ante el asalto de las huestes indígenas lideradas por el toki ${ }^{3}$ Anganamón. El Imperio perdió el control sobre una vasta y estratégica zona que quedó bajo el dominio de las parcialidades mapuche-huilliche.

La situación antes descrita fue revertida a partir de 1645. Producto de una fracasada expedición holandesa, se determinó la fortificación de la Bahía de Valdivia y, tras ello, la refundación de la ciudad, que a los pocos años fue amurallada. En ese proceso se levantaron, durante el siglo XVIII, los dos torreones que en la actualidad son los únicos vestigios de la muralla y, por ende, de la memoria del pasado militar de la ciudad.

\section{Incursión holandesa: El paisaje se fortifica}

Durante más de 40 años, el sitio de la antigua plaza de Valdivia fue ocupado por vegetación propia de la selva de la zona, o así por lo menos se ha transmitido desde la visión europea. Aparentemente, el Imperio la había olvidado. Sin embargo, a nivel de despachos, Valdivia era un tema recurrente a causa de la situación de vulnerabilidad en la que se encontraba parte del territorio, sobre todo a partir de 1621, tras la ascensión al trono de Felipe IV y el cese de la vigencia del Pacto de Tregua, firmado en 1609. La pax hispánica había concluido, y la tensión internacional se hizo evidente. Esta situación propició el debate sobre los puntos estratégicos y vulnerables de un imperio asediado por diversas potencias, tanto en Europa como en sus territorios de ultramar. La antigua ciudad de Valdivia era uno de ellos.

Se generó entonces un nutrido intercambio epistolar sobre la factibilidad de edificar alguna fortificación en la zona. A favor y en contra, diversas autoridades en América y España, religiosos y laicos, dieron su parecer en relación a la pregunta de si Valdivia era o no la puerta del Imperio en el Pacífico sur.

Sobre este punto escribió, por ejemplo, don Iñigo de Ayala ${ }^{4}$, quien informó al gobernador de Chile, don Lope de Ulloa y Lemos (1618-1620), lo siguiente:

Viendo S. M. y su consejo lo que importa la población sobre que yo he hecho mucha instancia me mandó tomar aquel puerto y hacer planta de el y que deste paraje avise a vuestra señoría para que cuando yo llegue a el dicho puerto de Valdivia halle en el orden de vuestra señoría si será bien poblarle con esta gente o en otra ocasión (Col. Mss. de Medina, tomo 125, pieza 2250, fojas 140-174).

En otro momento, el 16 de abril de 1630, don Pedro Martínez de Prado 5 escribió que "parece imposible (terminar la guerra) no haciéndose la población de Valdivia cortando la guerra por aquella parte que es el comedio de la tierra del enemigo y el que asegura el venio de la nuestra" (Col. Mss. de Medina, tomo 130, pieza 2335, fojas 11-20). Una postura distinta fue defendida por don Luis Merlo de la Fuente ${ }^{6}$, quien en 1635 opinó lo siguiente:

Y en cuanto al punto segundo acerca de fortificar con dos fuertes la boca del puerto de Valdivia por haberlo introducido a V.M por llave del Perú y Chile digo señor que de tal manera es llave que después de cerrarla y fecha la fortificación caso negarlo que se diera lugar a hacerlo (que no conviene gastar a V. M. tan grande hacienda tan sin fruto) no cerrarán ni guardarán el mismo puerto por la anchura de su boca y otros, cuan lo más a ambos reinos. (Como se citó en Barros, 1884, p. 325)

\footnotetext{
3. En el mundo mapuche-huilliche la palabra toki hace referencia al líder militar.
}

4. Don Iñigo de Ayala fue procurador del Reino enviado a España por el gobernador don Lope de Ulloa y Lemos con la finalidad de reclutar 800 hombres para poder proseguir con la guerra.

5. Se desconoce el cargo que detentaba.

6. Don Luis Merlo de la Fuente, como oidor de la Real Audiencia de Santiago, sucedió al Gobernador Alonso García Ramón, en calidad de interino, entre 1610 y 1611, y regresó a Lima en 1612. 
Por otra parte, Santiago de Tesillo" (1635) opinaba que "lo seguro será que si hubiere esta unión ${ }^{8}$ durará lo que tardare la ocasión de pasar a cuchillo el rebelde de Chile al de Europa" (como se citó en Amunñategui, 1910, p. 245).

Así, se desarrolló una discusión al respecto con diversos argumentos y desde distintas perspectivas. Algunos alababan las condiciones del puerto, mientras que los más escépticos cuestionaban la calidad del mismo argumentando que existían otros más idóneos. Por otra parte, no faltaron quienes insistían sobre la riqueza aurífera de la zona.

Sin embargo, pese a los distintos pareceres, finalmente la dilatada discusión, que duró más de 40 años, fue zanjada por llegada de una expedición holandesa a las costas valdivianas en agosto de $1643^{\circ}$. Si bien dicha empresa fracasó, causó alarma general tanto en el Reino de Chile como en la capital virreinal, pues se había hecho realidad un temor que suscitó preocupación sobre la zona sur desde 1598.

El intento de invasión solo podía generar una posible acción: ocupar el puerto de Valdivia, tarea a la que se abocó no solo el gobernador de Chile, sino, muy especialmente, el virrey del Perú, don Pedro Antonio de Toledo y Leiva, marqués de Mancera ${ }^{10}$, quien dio los lineamientos para los trabajos de fortificación, iniciados en febrero de 1645 bajo la mirada técnica del ingeniero Constantino Vasconcelos ${ }^{11}$.

Una vez tomada la decisión, ante la necesidad de justificarla ante la Corona, el virrey escribió lo siguiente:

Repetidamente ha parecido en las juntas generales de ministros y soldados que el puerto no es indefenso como se pensaba... a una de las dificultades que hallaron los virreyes para ocupar Valdivia, fue el pedir los de Chile mil hombres y gran suma de hacienda, y un situado también disforme; y si hubo fundamentos para escusar estos gastos también eran mayores ahora que tanto importa socorrer a vuestra majestad cuando le obligan las guerras de España andar siempre con las armas en la mano... de aguardar la orden de nuestra majestad como lo más conveniente para acertar en la ocupación de Valdivia, después que allí salieron los enemigos había de resultar deshacerse todo, y entrar otra vez primero los holandeses, cargo mayor para el virrey, que ocupar sin nueva orden. (Col. Mss. de Medina, tomo 138, pieza 2525, fojas 1-45).

El resultado de los trabajos iniciados por orden virreinal fueron 17 enclaves, con categoría de castillos, fuertes y baterías, desde la Bahía hasta el río Cruces, en el interior del territorio. Ello permitió, conectar Valdivia con el Reino de Chile, así como facilitar el avance hacia zonas abandonadas a partir de Curalaba.

Durante 185 años, la Corona española mantuvo en Valdivia una importante fuerza militar con la calidad de plaza fuerte y rango de presidio, cuyo principal objetivo era impedir cualquier posible invasión, por lo que adquirió especial connotación para Lima y los virreyes. Esto lo graficó claramente el virrey don Luis Enríquez de Guzmán, conde de Alba de Liste, en una de las muchas ocasiones en las que se refirió a las fortalezas de la Bahía: "Por haber sido la población de Valdivia hechura de los Virreyes" (como se citó

\footnotetext{
7. Santiago de Tesillo, maestre de campo en Chile y corregidor de la ciudad de Concepción, también fue cronista de los sucesos que tuvieron lugar en el Reino. Entre sus obras se encuentra "Guerra de Chile, Causas de su Duración, Medios para su Fin".

8. Tesillo hace alusión a una posible unión entre indígenas y piratas.

9. Es importante recordar que el siglo XVII fue el siglo en el que piratas y corsarios, avalados por la Teoría de la Libertad de los Mares de Hugo Grocio, trataron de socavar el predominio español a nivel mundial.

10. El marqués debía actuar sin la aprobación de la Corona, puesto que el peligro era inminente, sobre todo a partir de la invasión holandesa al noreste brasileño. El monarca, por Real Cédula de 3 de junio de 1643, había ordenado excusar la fortificación.

11. En la historia de Valdivia, la figura de este ingeniero, a quien se le deben otras obras en el Virreinato, se pierde.
} 


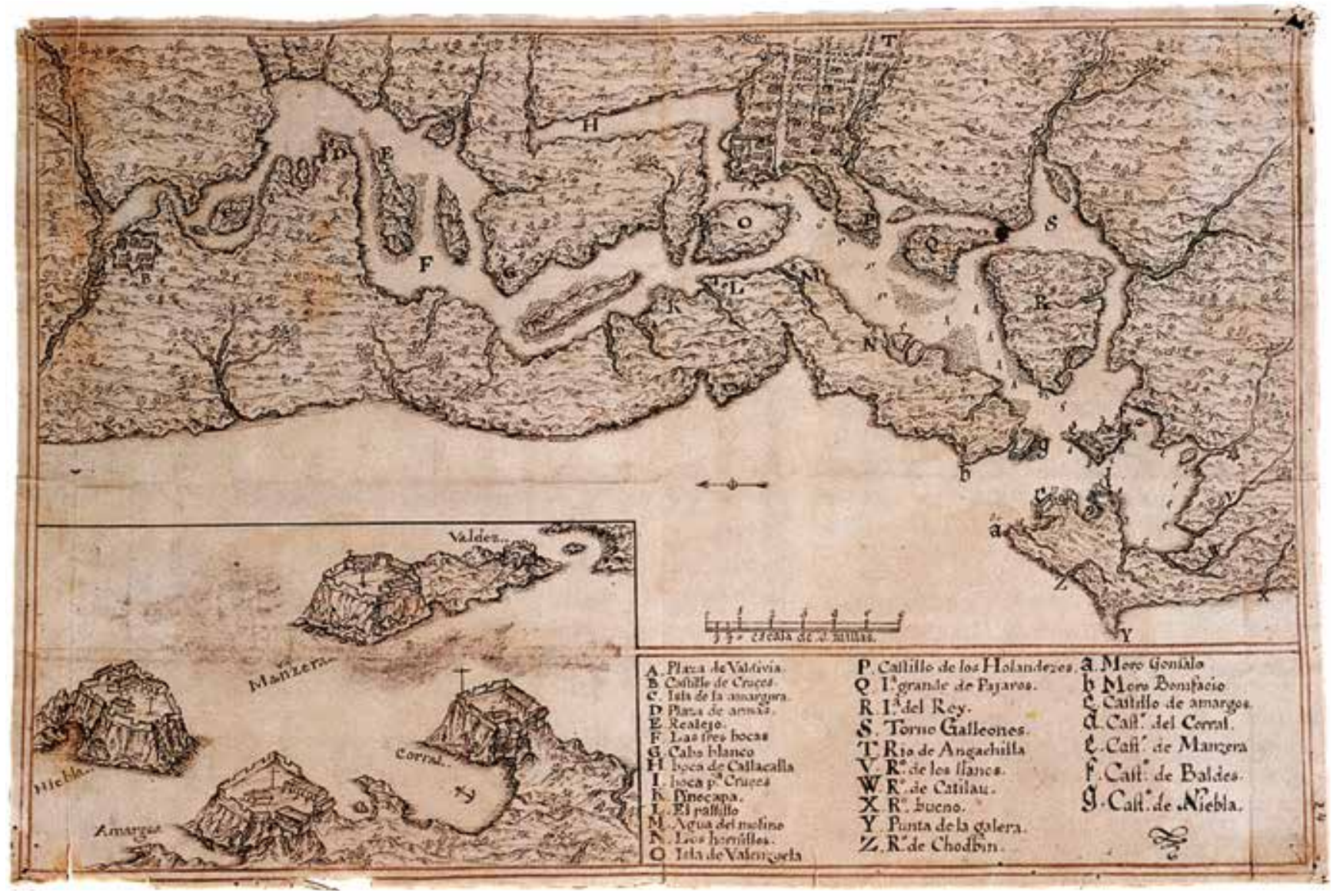

en Guarda, 2001, p. 176). Hombres y artillería esperaron el retorno de algún enemigo para poder desplegar su capacidad defensiva.

El sistema, en todo su conjunto, si bien tuvo grandes defensores, también tuvo detractores, que pusieron su capacidad defensiva en duda. Sin embargo, más allá de dichas discusiones, que se prolongaron tanto como la existencia misma de las fortificaciones, el territorio se transformó en un sólido enclave español hasta la expedición liderada por Lord Thomas Cochrane en febrero de 1820 (Figura 2).

\section{La ciudad se amuralla}

Fernando Cobos, en "Los Sistemas de Fortificación como Patrimonio Heredado" (2005), escribe lo siguiente:

De todos los grandes imperios, el español será, posiblemente, el que más fortificaciones haya construido o promovido en todos los territorios que directa o indirectamente controlaba.... Si la fortificación era, en definitiva, la consecuencia del desarrollo de la artillería que occidente utilizó para dominar el planeta a partir del siglo XVI, no puede extrañarnos que la arquitectura militar abaluartada se convirtiera en el símbolo, la marca, de este dominio y la Monarquía Hispánica, que apuntaló su imperio con baluartes frente otras potencias, hizo de este modo de fortificar una especie de estilo internacional de arquitectura que extendió por el mundo. (p. 271)

La ciudad de Valdivia fue parte de ese montaje escénico descrito por Cobos, y si bien el proyecto de fortificación iniciado en febrero de 1645 no contemplaba la refundación de la ciudad, el segundo gobernador de la Plaza Fuerte consideró que el proyecto era,
Figura 2. Plano del Puerto de Valdivia, 1742. En Flandes Indiano. Las Fortificaciones del Reino de Chile 1541-1826 (p. 119), por G. Guarda, 1990, Santiago de Chile, Chile: Universidad Católica. Este mapa se encuentra en el Archivo de Indias bajo la siguiente descripción: Mapa de la situación, puerto, terrenos y fortificación de la Plaza de Valdivia. 1742-8-20. 


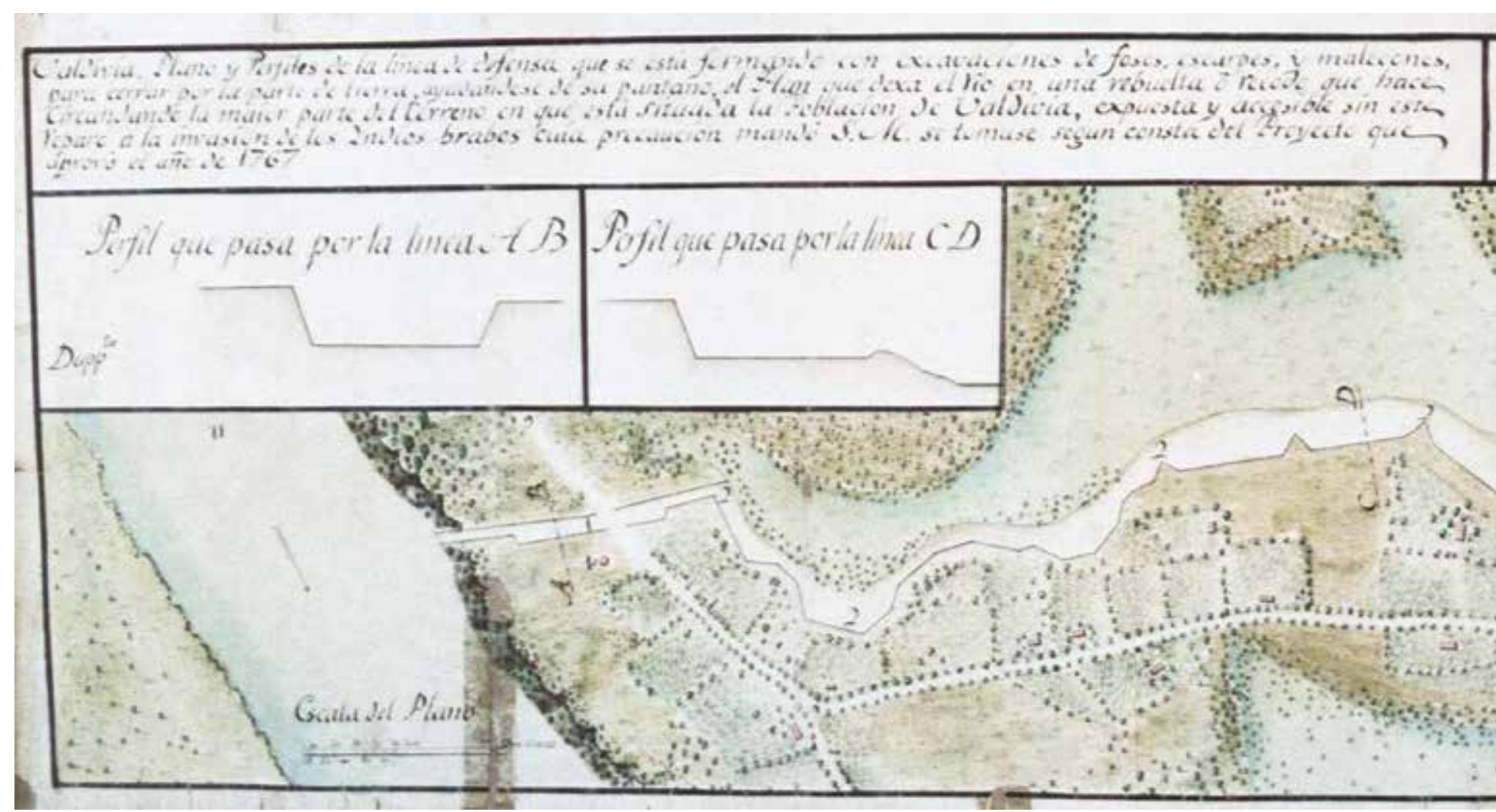

en primer lugar, viable gracias a de la existencia de parcialidades indígenas cristianas y por ende amigas, y, en segundo lugar, que a través de la refundación de esta se podría fortalecer el sistema defensivo y favorecer el avance hacia el interior del territorio. Por ello, don Francisco Gil de Negrete decidió refundar la ciudad, en su antiguo emplazamiento, el día 6 de enero de 1647. El jesuita y cronista Diego de Rosales, en Historia Jeneral del Reino de Chile, Flandes Indiano (1878), relata dicho momento:

Fueron apercibidos los soldados de machetes y los demás instrumentos para rasar la grande espesura de los montes, y aunque saltaron a tierra con mucha vizarría... se despojaron luego de ellas y comenzaron a trabajar con grandes alientos, abriendo camino hasta llegar a la plaza, donde se le preguntó al Capitan Martin de Santander, que iba en el exército y era natural de Valdivia, dónde caia la iglesia mayor, para donde fue guiando por entre la espesura después de cincuenta años que de aquella avia salido huyendo.... En ella tuvieron bien que desmontar y aunque la techumbre la consumió el fuego cuando el enemigo abrazó la ciudad, las paredes se conservaron enteras por ser de piedra de laxas que con el barro se aprietan. (p. 330)

Seis años tras la refundación, se inició el levantamiento de la primera muralla. Incendios, terremotos y la acción de los elementos del clima determinaron la necesidad de modificarla permanentemente, así como al sistema fortificado en general. Por esta razón, en 1756 se dio inicio a los trabajos de lo que sería la última muralla, sobre los cuales el historiador Gabriel Guarda (O. S. B.) en Nueva Historia de Valdivia (2001) relata:

La había levantado de piedra, añadiéndole los baluartes de que carecía: en junio de 1758 llevaba hechos tres lienzos "de estacada doble y con puntas a distancia de dos varas la una de la otra, unida la de atrás, de dos palmos más corta, y con entradas muy pequeñas para introducir tropa o hacer fuego", solución usada con éxito contra moros. (p. 300) 


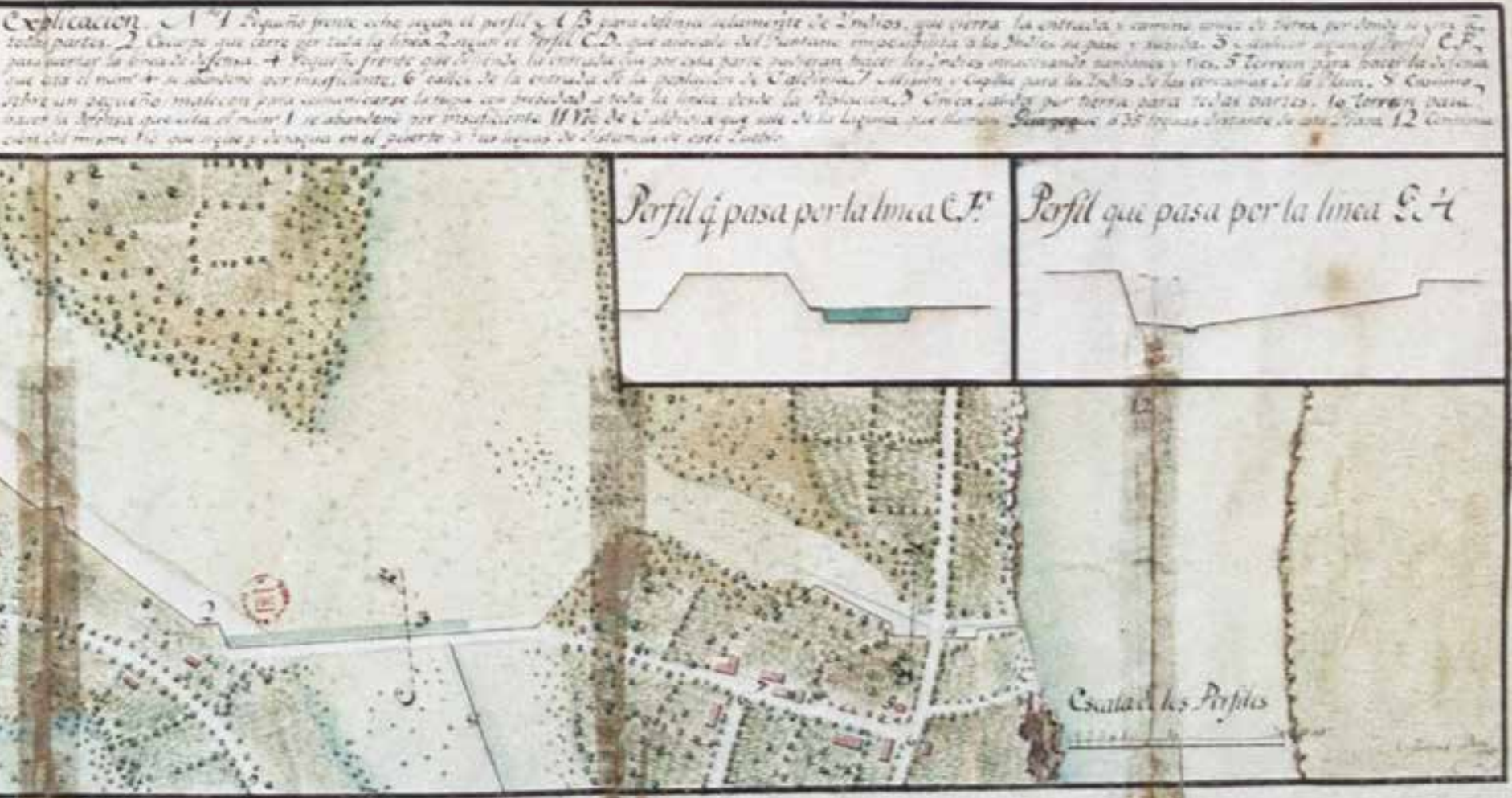

En 1774, frente a un posible ataque indígena, el gobernador de la Plaza, don Joaquín de Espinoza y Dávalos, ordenó la construcción de dos torreones ${ }^{12}$ con el objetivo de fortalecer el sistema defensivo de la ciudad, específicamente en los sectores oriente y sur. Este proyecto estuvo a cargo del coronel de ingenieros, Juan Garland ${ }^{13}$. Sobre este episodio, relata Guarda (1953) lo siguiente:

Se temió en aquella oportunidad la pérdida total de la plaza "para evitar esta fatal consecuencia-escribió Espinoza al presidente Jáuregui en marzo de 1774-no hallo otro arbitrio, que el de construir inmediatamente dos torreones semejantes a los de las costas de Andalucía contra moros". (p. 135)

De acuerdo a las descripciones realizadas por Guarda (2001), los torreones fueron diseñados con las siguientes características:

12. Los torreones fueron denominados del Barro y de Los Canelos, nombres que hacen alusión a elementos que identificaban sus respectivos emplazamientos Así, el primero se ubica en el sector oriente de la ciudad hacia la zona de los llanos, a donde para llegar se debía seguir el camino del mismo nombre, que con el paso del tiempo se conoció también como Calle Larga. En la actualidad es una de las arterias principales de la ciudad, denominada Ramón Picarte, y a través de ella se accede a la ruta Panamericana. Por otra parte, el torreón de Los Canelos, en el sector sur de la ciudad, se ubica en una zona que en los siglos coloniales se caracterizaba por la presencia de canelos, árboles ceremoniales en la cultura mapuche. A medida que la ciudad se fue expandiendo extramuros, el sector se comenzó a denominar Canta-ranas, puesto que era una entrada a humedales y se caracterizaba por la numerosa presencia de estos anfibios. En la actualidad en dicho torreón finaliza calle Yungay empieza la calle General Lagos. Ambas fueron declaradas como Zona Típica en 1991. Sobre los torreones, el historiador Gabriel Guarda señala que tras 1820 fueron reacondicionados, primero como molinos de viento y más tarde como almacenes de pólvora.

13. Juan Garland, de origen irlandés, ha sido considerado como uno de los grandes ingenieros del siglo XVIII. Llegó a Valdivia puesto que el rey, Fernando VI, solicitó "un hábil ingeniero capaz de dirigir las obras con acierto" (Guarda, 2001, p. 259).
Figura 3. Valdivia, Plano y perfiles de la línea de defensa (ca. 1785). En Flandes Indiano. Las Fortificaciones del Reino de Chile 1541-1826 (pp. 104-105) por G. Guarda, 1990, Santiago de Chile, Chile: Universidad Católica. Este mapa se encuentra en el Archivo de Indias con la siguiente descripción: Mapa de la situación, puerto, terrenos y fortificación de la Plaza de Valdivia. 1742-8-20. 
devenir Vol. 5, №10, JULIO-DICIEMBRE 2018, Pp. 29-46 - Estudios | ISSN 2312-7562 | E-ISSN 2616-4949

UnIVERSIDAD NACIONAL DE INGENIERÍA, LIMA

DOI: https://doi.org/10.21754/devenir.v5i10.597

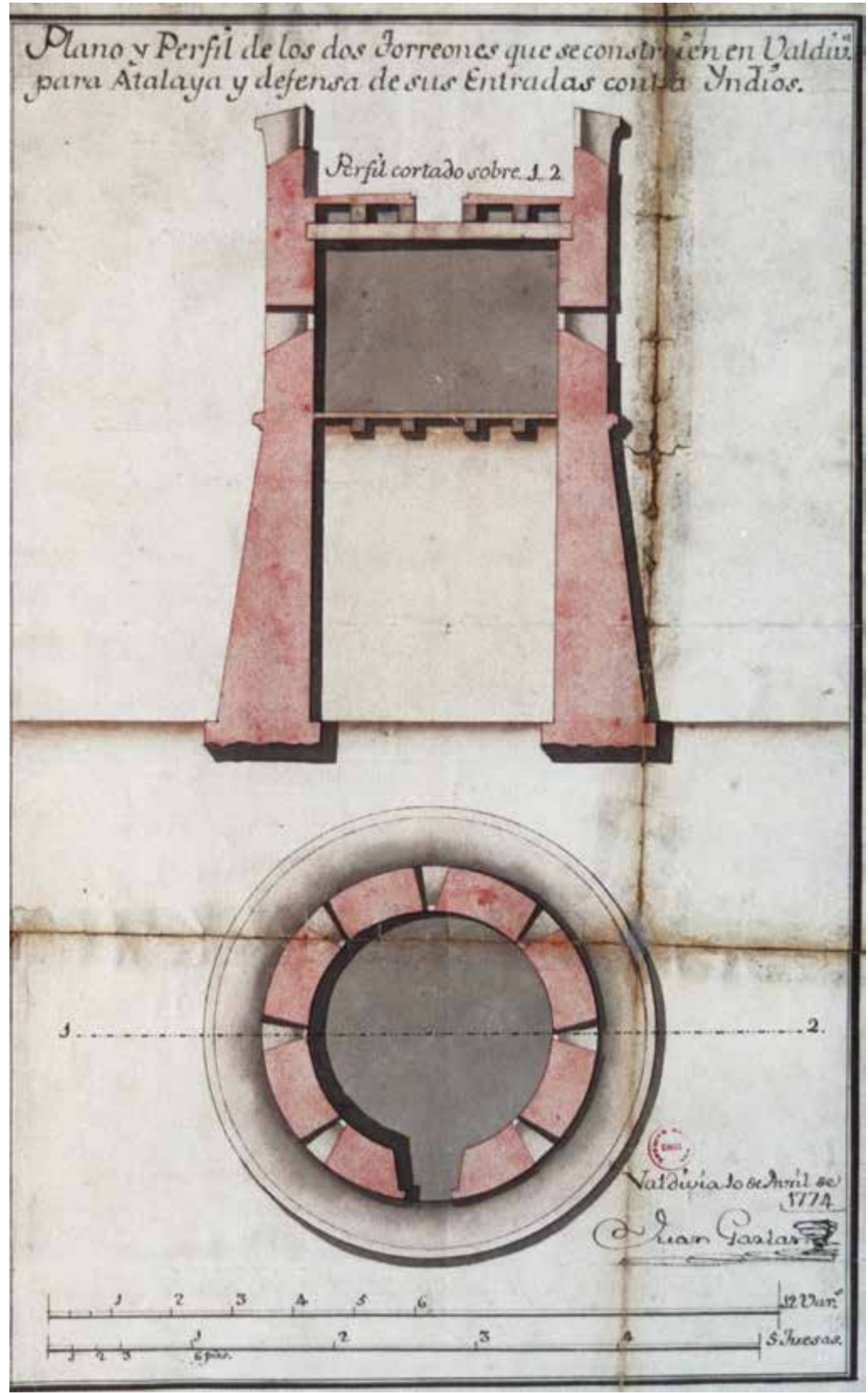

Figura 4. Plano y perfil de los dos torreones que se construyeron en Valdivia para Atalaya y defensa de sus entradas contra Indios, [s.n.], 1774. En Flandes Indiano. Las Fortificaciones del Reino de Chile 1541-1826 (p. 103), por G. Guarda, 1990, Santiago de Chile, Chile: Universidad Católica. Este mapa se encuentra en el Archivo Nacional Histórico de Chile, en el Archivo Nacional Histórico MAP № 94. 
El cuerpo bajo relleno, siendo lo único habitable el edículo superior con acceso externo por una escalera que se sube al interior, sirviendo a la vez para salir por la escotilla a la azotea, con gárgolas, y protegida de parapeto para cubrir a los fusileros... 7 varas de diámetro exterior en la base, $5.1 / 2$ en la corona de la almena, el primer cuerpo en talud, tiene 5 de alto y el total, 8.1/2 con un diámetro interior de 4; iguales, fueron óptimamente construidos en cal y ladrillo proveniente de la isla Valenzuela. (p. 305)

En relación al costo de la construcción, Guarda señala que se usaron "1,233 fanegas de cal y una arroba de fierro en 20 clavos para los maderos de la azotea" (2001, p. 306), y en lo referente su dotación, que "se hicieron capaces de contener un cabo y cuatro hombres que puedan manejar cañoncillos" (1953, p. 135).

Finalizando el siglo XVIII, el ingeniero Antonio Duce completó la muralla iniciada en 1756, mediante la adición de los dos torreones, y logró con ello el cierre definitivo de esta. Esos últimos trabajos determinaron que se le conozca como "Cerca de Duce":

De 1600 metros lineales, 120 presidiaros cortan los escarpes y excavan el foso en uno de los accesos: en 1785 avanzó a su conclusión, ajustada lo más posible a la topografía del sitio, determinando la necesidad de cortar el perímetro, la construcción de dos malecones perpendiculares, en forma de T, en el bajo de la calle de Henríquez, disminuyendo su amplitud y con ello su dotación... en 1794 se le cita con "foso que los une [a los torreones] y que ahondándole más pueden comunicar las aguas el río". (Guarda, 2001, p. 307) (Figura 3)

El proyecto defensivo quedó inconcluso, puesto que el objetivo final para la total defensa de la Plaza era, tras el arco de la muralla y de los torreones, utilizar el río como elemento defensivo definitivo abriendo entre las dos estructuras un canal para comunicar las aguas:

Cortando el perímetro exterior de ella con un foso de dos mil cuatrocientas varas de longitud, provisto en todo su curso con bastiones, terraplenes, muelles y calzadas, por el cual había que desviarse nada menos que el curso del caudaloso Calle Calle. (Guarda, 1953, p. 136) (Figura 4)

Sin embargo, la crisis dinástica y más tarde las guerras de independencia frenaron y truncaron el desarrollo de esta idea.

En cuanto a los torreones, es posible apreciar la forma en la que la corona abordó, desde la perspectiva militar, el asunto indígena y la asimilación a las luchas peninsulares contra el enemigo musulmán, tal como reseña Guarda (1953; 2001). Al respecto, resulta interesante el uso en Valdivia de estas estructuras en el último cuarto del siglo XVIII, cuando en Europa ya habían quedado en el olvido. Según Pedro Mora indica en "Tratados y Tratadistas de Fortificaciones: Siglos XVI al XVIII" (2000),

Su imponente estructura todavía se mantiene en pie, mostrándonos sus caponeras, barbacanas, amplio foso, escarpes y una gran galería transcurriendo a lo largo de las cortinas para prevenir posibles acciones enemigas por medio de minas de pólvora. Su planta rectangular ofrece la apariencia de castillo más que de una plaza fortificada. El espesor y la altura de sus muros de ocho metros, los escarpes en talud, los cuatro torreones en las esquinas plataforma en el centro de las cortinas para emplazar artillería y sus cuatro barbacanas para la defensa exterior, muestran bien a las claras su importancia. Pese a todo, a mediados del siglo XVI, en consonancia con las nuevas teorías poliorcéticas, el impresionante conjunto fortificado aparecía ya caduco. (p. 9)

Con dichas palabras, el autor describe el último castillo en el que se contemplaron torreones, el de Sales en el Rosellón, una fortificación que, en palabras de Mora, era un claro ejemplo de transición desde lo medieval hacia lo moderno.

De acuerdo a las descripciones sobre la Escuela de Ingenieros, en general se tendió a "reforzar los muros con gruesos terraplenes y sustituir baluartes pentagonales, en 
lugar de los antiguos torreones" (Gijón, 2011, p. 42), cambios que sí se evidenciaron en las fortificaciones de la Bahía de Valdivia, denominadas abaluartadas. Por ello, es interesante como, mientras que en Europa finalizando el siglo XVIII la ciudad amurallada es cuestionada, en la Plaza de Valdivia se produce lo contrario:

Este modelo de ciudad cerrada cuya estructura está condicionada por criterios militares de defesa, entra en crisis irreversible a la par que el propio modelo socio-económico que la sustenta. La expansión del régimen liberal a golpe de sucesivas revoluciones burguesas horada los recintos amurallados cuestionando sus fundamentos militares, fiscales e ideológicos. Los impulsos para "salir fuera" eran tan fuertes que en España será el propio rey Carlos IV quien, a través de una disposición de origen bajomedieval vigorizada en 1804, prohíbe salir a edificar en los arrabales, fuera de los recintos amurallados... Era un síntoma evidente de la lucha entre quienes en estos momentos defienden dos modelos de ciudad antagónicos; el modelo preexistente y el modelo abierto que propugna a burguesía y que se ira materializando a medida que se apodera del espacio urbano. (Reguera, 1991, p.136)

La construcción de la muralla o cerco fue avalada por la población civil, que percibió en dicha defensa una forma de asegurar la explotación económica del territorio y a la par garantizar el avance sobre este. Era evidente la necesidad, para las autoridades, no solo de defender la bahía sino de, además, avanzar sobre la zona de frontera interna, un territorio ocupado por parcialidades amigas y enemigas. A las primeras había que protegerlas; a las segundas, que someterlas. Fue un proceso de frontera abierta en el que participaron, como señala Urbina (2009),

Los pobladores y residentes de la plaza, interesados en colonizar las "pingües tierras" de los Llanos y las autoridades centradas en reabrir el camino real para establecer comunicación con Chiloé, y por el otro, los caciques que vieron en la plaza el respaldo necesario en sus conflictos con otras parcialidades. (p. 195)

A ello se sumaba, evidentemente, la Iglesia, cuya misión evangelizadora se encontraba definida en las bulas alejandrinas. En resumen, los objetivos de las autoridades fueron siempre "fomentar la autarquía económica de la plaza; mejorar la situación económica de su población y establecer relaciones hispano indios a través de los misiones y de los capitanes amigos" (Urbina, 2009, p. 196).

Así como las fortificaciones de la bahía, la ciudad amurallada con sus torreones fue un baluarte a través del cual se fortaleció la ocupación del territorio. La necesidad de defensa de este, que explica el sentido de la muralla, dio un giro a partir del advenimiento de la casa de Borbón. Se impuso una mirada científica de la guerra y los sistemas defensivos, una mirada razonada sobre el espacio y, por ende, del territorio, al fomentarse la ocupación de este por parte de la población civil, encargada de explotarlo económicamente. La muralla se transformó en garante y aliciente para la expansión en el interior de este. Un ejemplo que caracteriza esta situación fue la resistencia que generó la Real Orden de 1760, que daba instrucciones para trasladar la ciudad a la isla de Mancera. La población se opuso, argumentando que significaría un retroceso ante los indígenas.

Evidentemente la penetración hacia los valles circundantes era ya un éxito y, por lo tanto, el repliegue de la ciudad hacia la bahía implicaba una crisis de carácter económico y también estratégico, puesto que el avance logrado a partir de Valdivia era significativo. De darse, las haciendas quedarían sin protección, puesto que la ciudad, con su carácter de plaza fuerte, era garante no solo de la paz sino, especialmente, de la posibilidad de expansión, pues las fortificaciones permitían el desplazamiento de los sacerdotes, tras cuya huella evangelizadora se desplazaba la población civil perteneciente al grupo hispano-criollo.

Gracias a la ciudad amurallada se sentaron los pilares de la ocupación absoluta del territorio, motivada esencialmente por intereses económicos, y la expansión hacia zo- 


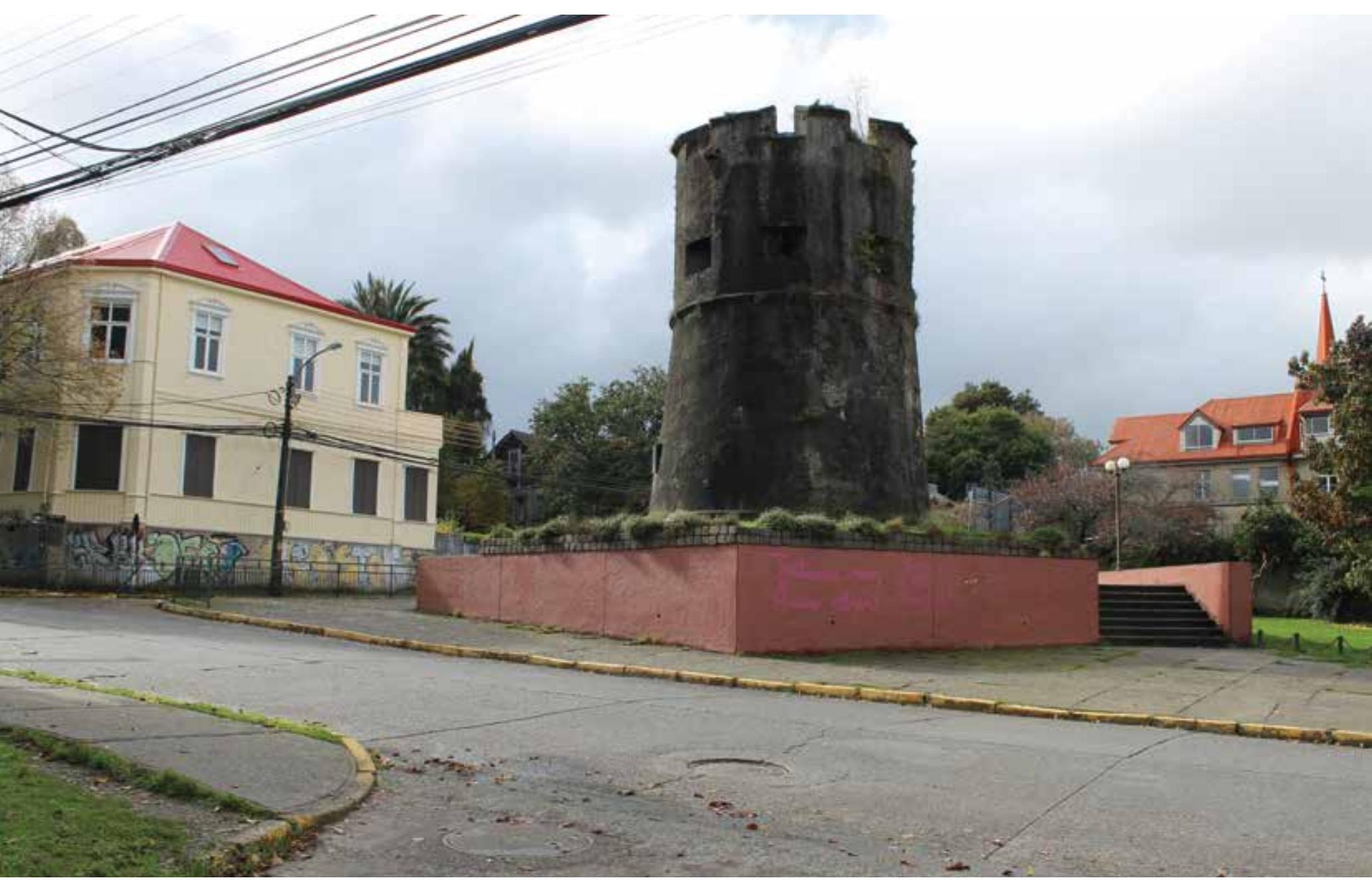

nas que permitiesen ampliar la explotación agrícola y ganadera de la Monarquía. Las fortalezas se transformaron así en el panóptico desde el cual se aseguraba el control y la explotación del territorio. Todo ello fue planificado, ordenado y financiado desde Lima, que en calidad de capital virreinal asumió el dilema valdiviano como propio, en pos de la seguridad del Imperio. Desde la ciudad ya enunciada, pertrechos, hombres y artillería eran permanentemente despachados, vía el Puerto del Callao, hacia Valdivia.

\section{Torreones: Vestigios del pasado}

La ciudad murada se insertó en una de las muchas fronteras de guerra que mantenía el Imperio. Con ello se cumple lo que Juan de Á. Gijón (2011) considera como el proceso de identificación de fronteras con fortalezas a partir del siglo XVI: "Hacer frontera al enemigo" (p. 96). Los torreones de Valdivia fueron, sin lugar a dudas, un brazo del poder real. Así fueron visualizados en el siglo XVIII, cuando la ciudad amurallada fungía como símbolo de un poder superior: el poder divino representado por el monarca. Tal como señala Sennett en Carne y Piedra. El Cuerpo y la Ciudad en la Civilización Occidental (1997), refiriéndose a las palabras de Vitrubio, "la majestad del Imperio [se] expresa en la inminente dignidad de los edificios públicos" (p. 101). El mismo autor afirma que "el Imperio romano había hecho inseparable el orden visual y el poder imperial: el emperador necesitaba que su poder fuera visto en los monumentos y en las obras
Figura 5. Torreón de Los Canelos, ubicado en el sector sur de la muralla. Fotografía de R. Brümmer, 2018. 
públicas. El poder necesita de las piedras" (p. 96). Por otra parte, como señala Foucault en Bentham Jeremías, el Panóptico (1979),

Desde finales del siglo XVIII la arquitectura comienza a estar ligada a los problemas de población, de salud, de urbanismo. Antes, el arte de construir respondía sobre todo a la necesidad de manifestar el poder, la divinidad, la fuerza. El palacio y la iglesia constituían las grandes formas, a las que hay que añadir las plazas fuertes; se manifestaba el poderío, se manifestaba el soberano, se manifestaba Dios. (p. 11)

La ciudad amurallada de Valdivia representaba ese poder. Sin embargo, con la llegada del siglo XIX aparecieron los cuestionamientos y el rechazo al poder real, y sus varias manifestaciones. Producto de ello, la naciente República construyó un relato en el que se invisibilizaron algunos momentos de la historia colonial ${ }^{14}$. Ello permite plantear una serie de interrogantes, por ejemplo, ¿qué representan los torreones en la actualidad? ¿cuánto de su pasado militar se encuentra presente en la memoria de la comunidad?

No se debe olvidar que la memoria histórica es "una memoria prestada de acontecimientos del pasado que el sujeto no ha experimentado personalmente y que se construye y modifica mediante lecturas, fotografías, videos y otro tipo de registros" (Menjívar, 2005, p. 11). Por otra parte, al recordar se reconstruye el pasado desde un presente que, de acuerdo a su estructura simbólica, "modela, recrea, olvida e interpreta de diversos modos" (Menjívar, 2005, p. 12). Por ello, al recordar, también se olvida.

Sobre esta realidad escribe Fernando Cobos en "Los Sistemas de Fortificación como Patrimonio Heredado" $(2005)^{15}$ lo siguiente:

Apenas acabó el video, se volvió hacia mí y me dijo “pero entonces, papá, ¿nosotros -los buenos- quiénes somos?" Evidentemente, para los españoles del siglo XXI, la identificación histórica con cartagineses o romanos no nos crea ningún trauma de identidad nacional. (p. 272)

En cuanto a las preguntas planteadas en líneas anteriores, Mauricia Dominguez, en "La Temporalidad en el Patrimonio, el Conflicto de la Permanencia" (2012), plantea que

En términos de arquitectura el patrimonio está ligado a la concepción moderna del culto a la conservación del monumento histórico o artístico. Desde las primeras creaciones humanas un monumento se orienta a perpetuar la memoria colectiva de las generaciones futuras, ha sido una nota recordatoria para mantener un hecho o hazaña siempre vivo. (p. 124) (ver Figuras 5 y 6 )

¿Mantiene los torreones vivas sus hazañas? Se trata de un paisaje arquitecturado declarado como Monumento Histórico en el año 1926, estatus que fue ratificado en 1928 bajo el argumento del artículo Vo del Decreto $3,500^{16}$ de 19 de junio de $1925^{17}$ :

14. El Estado de Chile se construyó en la zona comprendida entre los ríos Copiapó, por el Norte y Bio Bio, por el Sur. Ese fue el Chile que tras la conformación de la Primera Junta de Gobierno, el 18 de septiembre de 1810, transitó hacia la Independencia en febrero de 1818. Los territorios al norte del río Copiapó y al sur del Bio Bio, así como el territorio en Oceanía correspondiente a Isla de Pascua, además de la zona sur austral, se fueron incorporando durante el siglo XIX. Ello ha determinado una mirada de carácter centralista sobre el territorio, que ha implicado el olvido de los procesos y los territorios existentes más allá de las fronteras iniciales, como la ciudad de Valdivia.

15. Es parte del relato de su experiencia en el Centro de Interpretación de la Muralla Púnica, cuyos restos se encuentran en la ciudad de Cartagena, España.

16. Mediante este decreto se originó la comisión encargada de la vigilancia y conservación de los monumentos históricos nacionales.

17. Con esta declaratoria queda bajo el alero de la Dirección de Archivos y Museos (en la actualidad en restructuración por la creación del Ministerio de las Artes y el Patrimonio), a diferencia de otros sistemas fortificados, que han quedado bajo dependencia del Ejército. Por lo tanto, su uso militar quedó circunscrito claramente a la etapa colonial, hasta el año 1820 
Que la 5a Conferencia Pan-Americana celebrada en Santiago el año 1923 tomó resoluciones concretas sobre la preservacion i conservación de los restos históricos i arqueolójicos que existen en los países americanos, recomendando a los Gobiernos la dictación de leyes que obliguen a los particulares a denunciar ante las autoridades los hallazgos arqueolójicos i ruinas históricas e impidan la esplotacion con fines de lucro, de los objetos que de ellos se estraigan. (párr. 6)

Sin duda, en la actualidad, la declaratoria corresponde a la conceptualización realizada por Krebs y Schimdt-Hebbel en "Patrimonio Cultural: Aspectos Económicos y Políticas de Protección" (1999):

El patrimonio cultural de una nación comprende todos aquellos bienes que son expresiones y testimonios de la creación humana propios de ese país. Es el conjunto de edificios, industriales,... que dan cuenta de la manera de ser y hacer de un pueblo. Dicho patrimonio es todo aquello que le confiere una identidad determinada a un país.... Estos bienes son preservados porque individuos o la sociedad, a través de las organizaciones creadas para ello, les confieren algún significado especial, ya sea estético, documental, histórico, educativo o científico. (p. 209)

La declaratoria de los torreones como Monumento Histórico tuvo lugar en un momento político caracterizado como Estado policial (Correa, Figueroa, Jocelyn-Holt, Rolle, Vicuña, 2001, p. 103), tal como se conoce al gobierno del general Carlos Ibañez del Campo, que pretendía construir un nuevo Chile y, sobre todo, consolidar la identidad nacional en una década caracterizada por una crisis política y económica que convulsionó a la sociedad de la época, con lo cual emergieron una serie de conflictos entre los que se encuentra el identitario. Sobre este aspecto se plantea, Bauman plantea que "La cuestión de la identidad también se asocia con la quiebra del estado de Bienestar y el crecimiento posterior de una sensación de inseguridad" (2007, p. 17). Así, los elementos militares adquirieron relevancia en tanto una forma de reforzar al Estado nación. Al respecto, Bauman (2007) indica lo siguiente:

La idea de identidad nació de la crisis de pertenencia y del esfuerzo que desencadenó para salvar el abismo existente entre el "debería" y el "es", para elevar la realidad a los modelos establecidos que las ideas establecían, para rehacer la realidad a imagen y semejanza de la idea. (p. 40)

Dicha inseguridad se hizo presente en Chile durante la década del 20 del siglo XX, lo que hizo necesario rescatar algunos aspectos del pasado con la finalidad de generar un sentido de comunidad e identidad nacional, puesto que

Tiempo y espacio juegan un papel importante en el sostenimiento de la memoria: el tiempo en la medida que la memoria vive mientras la adscripción al grupo permanece y el espacio en tanto que la memoria está vinculada a imágenes espaciales. (Menjívar, 2005, p. 11)

Sin lugar a dudas, la identidad se funda en el no olvido, pues es el recuerdo el vinculante social. Por ello, la preservación de los vestigios de la muralla resulta un factor sustancial para la conservación de la memoria, en cuya custodia el patrimonio cultural juega un rol fundamental. Como se señaló en el Tercer Seminario ICOMOS, en Sevilla, en el punto Conclusiones y Recomendaciones Relativas a las Ciudades Históricas,

Como documentos vivos nos ofrecen una lectura directa del substrato histórico en el que se fundamenta la particular idiosincrasia y la genuina identidad cultural de cada pueblo. Así, los valores intangibles representados a través del patrimonio físico expresan la personalidad histórica de los distintos pueblos y ciudades y los valores sociales, económicos y éticos sobre los que se asienta su evolución. (párr. 1)

Continúa la recomendación con las siguientes palabras: "La pérdida de estos soportes físicos conlleva la de los valores inmateriales que entrañan y afecta negativamente al equilibrio espiritual del ser humano y a su normal desarrollo" (párr. 2). Sin embargo, 
es evidente que la cultura, tanto en su dimensión material como inmaterial, no tiene igual sentido para toda la comunidad. La valoración del patrimonio se encuentra íntimamente ligada a la historia, tradición y memoria de la comunidad de pertenencia. Al respecto, Modesto García plantea en “Territorios de Identidad Urbana: Entre las Glorias del Pasado y el Futuro 'Líquido"' (2012), lo siguiente:

Pero es más, la consideración de qué es y que no es - ¿todavía?- Patrimonio por parte de la organizaciones internacionales en ello competentes; tanto como la misma consideración por parte de los diferentes Estados o grupos institucionalmente organizados, es en principio arbitraria. No hay un canon exacto que describa y defina qué es o qué debe ser Patrimonio. Lo que para unos es claramente un bien patrimonial puede ser para otros lesivo; pueden considerarse herencias culturales como bienes y que hayan sido agravantes para otros miembros de la misma o de distinta sociedad. Toda la tradición colonial, pongamos por caso, puede ser considerada una herencia cultural apreciable (la arquitectura, infraestructuras, modalidades de sistema político, historia oral, viajes, parajes...) para Occidente -si se me permite esta denominación no carente de ambigüedad- pero, a la vez, puede ponerse muy en duda que signifique lo mismo para grandes zonas de lo que -también con grandes dosis de opacidad- llamamos Tercer Mundo. (p. 213)

Por ello fue meritorio que entre los primeros Monumentos Nacionales declarados en Chile estuviesen los torreones de Valdivia. Sn embargo, ese acto jurídico impuesto ha opacado el valor que estos tienen. Por ejemplo, la declaratoria no explica que los torreones también eran conocidos, en España, como "torres vigía", visibles aún en zonas de contacto entre los antiguos Reinos de Castilla y Granada, así como en otras áreas de frontera. Tal como plantea Juan Gijón (2011), pueden encontrarse en Gerona, el antemural de Barcelona, Lérida, Tarragona, Valencia, Alicante, etc. La declaratoria no registra que se levantaron para someter a la población mapuche-huilliche, razón por la que se recurrió a formas militares que en Europa eran parte del pasado militar. Tampoco existe información sobre quiénes debieron ejecutar las obras de construcción: presidiarios o desterrados, hombres que "a ración y sin sueldo" (Andazabal, 2007, p. 53) cumplían su condena en el Presidio de Valdivia.

Retomando a Cobos (2005), resulta interesante su planteamiento sobre la percepción que se tiene sobre las fortificaciones:

Sin embargo, la percepción de la fortificación moderna como patrimonio monumental no ha sido unánime ni generalizada hasta hace pocos años y varía sustancialmente de unos lugares a otros. El hecho de que esta fortificación se concentrara en los límites fronterizos o en puntos singulares para el control de cada país. (p. 271)

Sin lugar a dudas, la ciudad murada de Valdivia fue parte de ese escenario ilustrado por Cobos. Quizás para la mayoría son simples torres que se han transformado en postales que identifican a la ciudad de Valdivia, pues no hay otras iguales en Chile. Así, por ejemplo, Recaredo Tornero (1872) indica lo siguiente:

En los costados sur i oriente de la ciudad existen dos torreones de 10 metros de altura i 6 de diámetro, construidos en el siglo pasado i destinados al resguardo i defensa de la ciudad contra los ataques de los indios. La posición es excelente, pues domina entradas de la ciudad por el río i por tierra. Estos pequeños fortines están, el uno abandonado i el otro destinado para servir de depósito a los pertrechos de guerra de propiedad fiscal. (p. 367)

En la misma línea, Paul Treutler, en “Andanzas de un Alemán en Chile, 1851-1863: Rostro de Chile" (1882), graficó el paisaje urbano y los torreones de la siguiente manera:

Más allá se veían las ruinas de la antigua muralla de la ciudad, sobre las cuales se elevaba una torre maciza bastante alta. Desde ahí la calle se seguía extendiendo más allá alternando casas y huertas, con muchos manzanos y canelos, dando éstos últimos el nombre al barrio... La calle 
más larga era la que se dirigía desde la plaza principal hacia el Este; bajaba bastante abruptamente y también en esta parte se elevaba una antigua torre sobre las ruinas de las murallas de la ciudad. (p. 287)

Ambos autores solo realizan una descripción, y queda fuera de su relato la razón de su construcción, el significado de su historia y la memoria que descansa en la fría piedra que los caracteriza. A ambos torreones les han arrebatado su esencia, proceso al que remite Mauricia Dominguez (2012):

Así, ni siquiera las pirámides pudieron cumplir el objetivo para las que fueron creadas, nos encargamos de convertirlas en atractivos turísticos vacíos de contenido pero impresionantes a la vista, el ancla que atrae cada año a Egipto miles de turistas, mejorando la economía local. Muchos no saben ni siquiera que van a ver, pero es importante poner el cotejo en la lista de los 100 lugares que ver antes de morir. (p. 125)

Sin lugar a dudas, "reconocemos nuestras ciudades por sus atributos clave codificados,... Los elementos de la ciudad (tejidos, hitos, espacios libres, etc.) construyen estructuras de significado, que asumen papeles diversos según el momento histórico" (Pardo y Mérida, 2012, p. 661). En la actualidad, producto de la incertidumbre, de crisis identitarias y del uso comercial del patrimonio, en este caso de los torreones, la sustracción de su sentido y la desvinculación con su origen es un riesgo difícil de evitar.

\section{Conclusiones}

Tras la incorporación de Valdivia a la República de Chile en 1820, y la pérdida de la calidad de presidio y plaza fuerte que ostentó durante la Colonia, poco a poco fueron desapareciendo los vestigios de su muralla. Sin embargo, los dos torreones no solo lograron sobrevivir el saqueo y la destrucción causados por la expedición de Lord Thomas Cochrane, sino también a incendios, a terremotos y al crecimiento natural de la ciudad.

Así, los torreones del Barro y de Los Canelos han perdurado como mudos testigos de un pasado militar reflejo de la política de la Monarquía frente a la población aborigen. Fueron el medio a través del cual la Corona intentó dominar a la población mapuche-huilliche; son recuerdo de la mirada que se tuvo sobre el territorio $y$, por ende, el símbolo de la gloria y grandeza del Imperio, pero también de la derrota de quienes habitaban el territorio antes de 1552.

Sin embargo, ¿cuánto de dicha memoria es transmitido en la actualidad? A través de los años, los torreones se han convertido en una de las postales más conocidas de la ciudad de Valdivia. Descritos por científicos y viajeros, destino obligado para los turistas, telón de fondo para ferias y recitales, imagen en afiches y souvenirs, sin lugar a dudas se han transformado en uno de los muchos bienes de consumo que ofrece la ciudad.

Sin embargo, nada de ello refleja el objetivo que justificó su construcción ni la visión que, durante el siglo XVIII, tuvo la Corona al enfrentar a sus enemigos y a la vez proteger a las parcialidades amigas con la finalidad de avanzar sobre el territorio, lo cual determinó que se emplearan elementos propios de la arquitectura militar medieval, "solución usada con éxito contra moros" (Guarda, 2001, p. 300), en la América colonial.

En los tiempos líquidos, en el mundo globalizado, quizás cobra mayor relevancia la necesidad de identificar en forma clara los valores que contienen los bienes patrimoniales. El signo no debe separarse de su referente y el significante debe explicar el significado, razón por la que los torreones de Valdivia son garantes de la memoria de la ciudad amurallada, los soportes de la identidad de quienes han habitado y habitan la vieja ciudad colonial. 


\section{Referencias}

Álvarez, R. (abril, 2009). Le Prestre. Sus aportes en cuestión de fortificaciones. Trabajo presentado en el V Seminario de Ciudades Fortificadas, Montevideo, Uruguay. Recuperado de http:// cidadesfortificadas.ufsc.br/files/2011/03/2009_5sem_palestra_Le-Prestre.pdf.

Amunátegui, M. (1910). Los precursores de la independencia de Chile. Santiago de Chile, Chile: Barcelona.

Andazabal, R. (2007). Criminalística peruana en el siglo XVIII. Lima, Perú: Universidad Nacional Mayor de San Marcos.

Barros, D. (1884). Historia Jeneral de Chile. Santiago de Chile, Chile: Rafael Jover.

Bauman, Z. (2007). Identidad: Conversaciones con Benedetto Vecchi. Buenos Aires, Argentina: Losada.

Cavaletti, A. (2010). Mitología de la seguridad. La ciudad biopolítica (2a ed.). Buenos Aires, Argentina: Adriana Hidalgo.

Cobos, F. (2005). Los sistemas de fortificación como patrimonio heredado. En A. Cámara (Comp.), Los ingenieros militares de la monarquía hispánica en los siglos XVII y XVIII (pp. 271-282). Madrid, España: Fernando Villaverde.

Correa, S.; Figueroa, C.; Jocelyn-Holt, A.; Rolle, C.; \& Vicuña, M. (2001). Historia del siglo XX chileno. Santiago de Chile, Chile: Sudamericana.

Decreto № 3.500, Establece la organización de la Comisión encargada para la vigilancia y conservación de los monumentos históricos nacionales. Santiago de Chile. 19 de junio de 1925. Recuperado de https://www.leychile.cl/Navegar?idNorma=1069367

Dominguez, M. (2012) La temporalidad en el patrimonio, el conflicto de la permanencia. En O. Niglio (Ed.), Paisaje cultural urbano e identidad territorial (pp. 121-130). Florencia, Italia: Esempi di Architettura. Recuperado de https://dialnet.unirioja.es/servlet/articulo?codigo=5259704.

Estellé P. \& Couyoudmian, R. (1968). La ciudad de los Césares: Origen y evolución de una leyenda (1526-1880). Revista de Historia, 7, 283-309.

Foucault, M. (1979). Bentham Jeremías, el panóptico. Madrid, España: La Piqueta.

García, M. (2012). Territorios de identidad urbana: Entre las glorias del pasado y el futuro "líquido". En O. Niglio (Ed.), Paisaje cultural urbano e identidad territorial (pp. 211-222). Florencia, Italia: Esempi di Architettura. Recuperado de https://dialnet.unirioja.es/servlet/articulo?codigo $=5259704$.

Gijón, J. (2011). El cinturón militar defensivo español en 1808. Torres, fortalezas abaluartadas y plazas fortificadas de las costas y fronteras españolas antes de la guerra de independencia. Monte Buciero, 15, 95-159. Recuperado de https://dialnet.unirioja.es/servlet/articulo?codigo $=4014701$.

Guarda, F. (1953). Historia de Valdivia 1552-1952. Santiago de Chile, Chile: Cultura.

Guarda, G. (O.S.B.). (1990). Flandes indiano. Las fortificaciones del Reino de Chile 1541-1826. Santiago de Chile, Chile: Universidad Católica.

Guarda, G. (O. S. B.). (2001). Nueva Historia de Valdivia. Santiago de Chile, Chile: Universidad Católica.

International Council on Monuments and Sites. (2001). El valor intangible del patrimonio. Recuperado de http://www.esicomos.org/Nueva_carpeta/LIBRO_CRITERIOS/SEVILLA.htm

Krebs, M. \& Schimdt-Hebbel, K. (1999). Patrimonio cultural: Aspectos económicos y políticas de protección. Perspectivas en Política, Economía y Gestión, 2(2), 207-245. Recuperado de http:// www.dii.uchile.cl/ revista/

Liewald, L. (2012). Club de Yates Valdivia 1912-2012. Cien años de travesías en el Mar del Sur. Santiago de Chile, Chile: Universidad San Sebastián.

Menjívar. M. (2005). Los estudios sobre la memoria y los usos del pasado: Perspectivas teóricas metodológicas. Cuaderno de Ciencias Sociales, 135, 9-28. 
devenir Vol. 5, Nº10, JULIO - DICIEMBre 2018, pP. 29-46 - Estudios | ISSN 2312-7562 | E-ISSN 2616-4949 UNIVERSIDAD NACIONAL DE INGENIERÍA, LIMA

DOI: https://doi.org/10.21754/devenir.v5i10.597

Mora, P. (2000). Tratados y tratadistas de fortificaciones: Siglos XVI al XVIII. En H. Carlos (Comp). Las fortificaciones de Carlos V (pp.157-169). Madrid, España: Del Umbral.

Pardo, S. \& Mérida, M. (2012). Aproximación a las vistas panorámicas de ciudades como patrimonio urbano, territorial y de identidad local. O. Niglio (Ed.) Paisaje cultural urbano e identidad territorial (pp. 658-670) Florencia, Italia: Esempi di Architettura. Recuperado de https://dialnet.unirioja.es/servlet/articulo?codigo $=5259704$.

Reguera, A. (1991). Proyectar la ciudad para hacer la guerra. Polígonos, 1, 135-172. doi: 10.18002/ pol.

De Rosales, D. (S. J.). (1878). Historia Jeneral del Reino de Chile, Flandes Indiano. Valparaíso, Chile: El Mercurio.

Sennett, R. (1997). Carne y piedra. El cuerpo y la ciudad en la civilización occidental (3a ed.). Madrid, España: Alianza.

Tornero, R. (1872). Chile llustrado; guía descriptivo del territorio del territorio de Chile, capitales de provincia i de los puertos principales. Valparaíso, Chile: El Mercurio.

Treutler, P. (1882). Andanzas de un alemán en Chile: 1851-1863. Rostro de Chile. Santiago de Chile, Chile: Del Pacífico.

Urbina, M. (2009). La frontera de arriba en Chile colonial. Valparaíso, Chile: Universidad de Valparaíso. 